\title{
VARIASI JUMLAH TUMBUKAN PADA PEMADATAN \\ CAMPURAN BETON ASPAL MENGGUNAKAN BAHAN TAMBAH ANTI STRIPPING
}

\author{
Eko Wiyono", Anni Susilowati² \\ ${ }^{1,2}$ Jurusan Teknik Sipil Politeknik Negeri Jakarta, Jln. Prof. Dr. G. A. Siwabessy, \\ email:ww_eko@yahoo.co.id, anni_susilowati@yahoo.co.id
}

\begin{abstract}
The objectives of the research were to obtain the Marshall properties of asphalt concrete mixture mixed with variations of manual compact collisions and to determine the optimum number of compactions collisions in the asphalt concrete mixture using anti stripping additives. The independent variables in this research are variation of the number of compaction collisions of asphalt concrete as many as $2 x 50$, $2 \times 75,2 x 100,2 \times 125$ and $2 x 150$, with optimum asphalt content of $6 \%$, and Wetfix Be 0,3\% to optimum asphalt content. Marshall test method used in this research was based on SNI 06-2489-1991. The dependent variables (research parameters) included percent of cavities in the aggregate (VMA), percent of cavities in the mix, percent of cavities filled in asphalt (VFB), percent of cavity to mix (VIM), stability, melting, and Marshall Quotient. The result showed that the optimum number of compactions of asphalt concrete was $2 x 100$ with Marshall properties value fulfilling SNI 8198-2015 specification. In Asphalt concrete mixture with optimum asphalt content (KAO) of 6\%, Wetfix Be level of 0,3\%, optimum number of compactions of 2X100, could be obtained by Aggregate (VMA) cavity 17.50\%; Asphalt filled cavity (VFB) 76.50\%; Cavity to Mixture (VIM) 4,00\%; Stability of $1800.00 \mathrm{~kg}$; Melting of $3.75 \mathrm{~mm}$; and Marshall Quontient $500.00 \mathrm{~kg} / \mathrm{mm}$
\end{abstract}

Keywords: Anti Stripping, Collision, Compaction, Wetfix Be

\begin{abstract}
ABSTRAK
Tujuan penelitian untuk mendapatkan nilai properties Marshall campuran beton aspal dengan berbagai variasi jumlah tumbukan pemadatan dan menentukan jumlah tumbukan pemadatan yang optimum pada campuran beton aspal dengan menggunakan bahan tambah anti stripping. Variabel bebas pada penelitian ini adalah variasi jumlah tumbukan pada pemadatan pembuatan beton aspal sebanyak $2 x 50$, 2x75, 2x100, $2 x 125$ dan 2x150, dengan Kadar Aspal Optimum 6\%, dan Wetfix Be 0,3\% terhadap kadar aspal optimum. Metode pengujian Marshall berdasarkan SNI 06-2489-1991. Variabel terikat (parameter penelitian) meliputi persen rongga dalam agregat (VMA), persen rongga dalam campuran, persen rongga terisi aspal (VFB), persen rongga terhadap campuran (VIM), stabilitas, kelelehan, Marshall Quotient. Hasil penelitian didapat jumlah tumbukan pada pemadatan beton aspal yang optimum sebesar $2 x 100$ dengan nilai properties Marshall memenuhi spesifikasi SNI 8198-2015. Campuran beton aspal dengan Kadar Aspal Optimum (KAO) 6\%, kadar Wetfix Be sebesar 0,3\%, Jumlah Tumbukan Optimum 2X100, diperoleh Rongga terhadap Agregat (VMA) 17,50\%; Rongga Terisi Aspal (VFB) 76,50\%; Rongga terhadap Campuran (VIM) 4,00\%; Stabilitas 1800,00 kg; Kelelehan 3,75 mm; dan Marshall Quontient 500,00 $\mathrm{kg} / \mathrm{mm}$
\end{abstract}

Kata kunci: Anti Stripping, Tumbukan, Pemadatan, Wetfix Be

\section{PENDAHULUAN}

Faktor-faktor yang menyebabkan kerusakan struktural beton aspal adalah efek air, kendaraan kelebihan beban, dan aplikasi konstruksi perkerasan yang tidak memenuhi persyaratan teknis. Salah satu karakteristik yang paling penting dinilai dengan campuran beton aspal adalah daya tahan. Oleh karena itu, aspal perlu dimodifikasi dengan menambahkan suatu bahan yang dapat menaikkan mutu aspal maupun campuran beton aspalnya.

Penelitian [1] Pengaruh Penggunaan Serbuk Arang Tempurung Kelapa Dan Variasi Jumlah Tumbukan Terhadap Karakteristik Campuran Beton Aspal. Dari hasil penelitian tersebut diperoleh 
semakin banyak jumlah tumbukan dan serbuk arang tempurung kelapa cenderung meningkatkan nilai Marshall Quotient dan menurunkan karakteristik campuran beton aspal.

Penelitian [2] tentang Pengaruh Variasi Jumlah Tumbukan Pada Lapisan Aspal Buton Beragregat (LASBUTAG) Campuran Dingin (Coldmix) Dengan Modifier Pertamax Terhadap Karakteristik Marshall. Adapun variasi jumlah tumbukan yang dilakukan adalah 50, 75, 100, 125, 150, 175 dan 200 tumbukan persisi dengan waktu pemeraman campuran selama 24 jam. Hasil studi ini menerangkan adanya perbedaan nilai-nilai karakteristik Marshall yang nyata dari masing masing jumlah tumbukan yang dilakukan. Adapun jumlah tumbukan yang dibutuhkan agar diperoleh kualitas perkerasan LASBUTAG yang optimum adalah 137 tumbukan persisi.

Penelitian [3] Variasi Jumlah Tumbukan pada Campuran Beton Aspal terhadap Nilai Density dan Void in The Mix (VITM), bahwa pada variasi jumlah tumbukan dari $2 \times 150$ sampai $2 \times 400$ tumbukan memiliki persentase kisaran nilai VITM antara 50\% - 60\% terhadap jumlah tumbukan standar $(2 \times 75$ tumbukan). Hal ini sebagai indikasi bahwa segala jenis variasi tumbukan diatas tumbukan standar akan mengakibatkan kelelahan bahan, akibatnya bahan perkerasan menjadi rusak.

Untuk menutupi kekurangan gradasi superpave maka diperlukan penggunaan bahan tambah, zat anti pengelupasan (Anti Stripping Agent) yang merupakan zat adiktif yang dapat merubah sifat aspal dan agregat, meningkatkan daya lekat dan ikatan, serta mengurangi efek negatif dari air dan kelembaban sehingga menghasilkan permukaan berdaya lekat tinggi.
Penelitian ini menganalisis Variasi Jumlah Tumbukan pada Pemadatan Campuran Beton Aspal Menggunakan Bahan Tambah Anti Stipping, dengan target hasil penelitian jumlah tumbukan pada pemadatan yang optimum memenuhi spesifikasi [4].

\section{METODE PENELITIAN}

\section{Lingkup Penelitian}

Dalam penelitian ini pengujian dilakukan secara bertahap, yang terdiri dari pengujian agregat (agregat kasar, agregat halus, dan filler), pengujian aspal, dan pengujian terhadap campuran beton aspal.

Untuk pengujian agregat terdiri dari pengujian berat jenis, pengujian berat isi, analisa ayak, pengujian kadar air, dan pengujian kadar lumpur. Adapun Pengujian aspal terdiri dari pengujian berat jenis, pengujian penetrasi, pengujian daktilitas, pengujian titik nyala, pengujian titik lembek. Metode yang digunakan untuk pengujian campuran beton aspal menggunakan metode Marshall, di mana dari pengujian Marshall tersebut didapatkan hasil yang berupa stabilitas, flow, void in total mix (VITM), void filled with asphalt, dan kemudian didapatkan nilai Marshall Quotient (MQ).

\section{Variabel Penelitian}

Variabel bebas dalam penelitian ini adalah variasi kadar aspal 5,0; 5,5; 6,0; 6,$5 ; 7 \%$, variasi Wetfix Be 0,0; 0,$2 ; 0,3 ; 0,4 \%$ terhadap kadar aspal optimum dan variasi jumlah tumbukan $2 \times 50 ; \quad 2 \times 75 ; \quad 2 \times 100 ; \quad 2 \times 125 ; 2 \times 150$ Adapun variabel terikat (parameter penelitian) meliputi : kepadatan, prosen rongga dalam agregat, prosen rongga dalam campuran, prosen rongga terisi aspal, kelelehan, stabilitas, dan Marshall Quotient. 


\section{Lokasi dan Bahan-bahan Penelitian}

Penelitian ini dilakukan di laboratorium uji bahan jurusan Teknik Sipil Politeknik Negeri Jakarta. Adapun bahan-bahan yang digunakan dalam penelitian ini adalah aspal Esso, agregat kasar batu pecah, abu batu dan filler semen portland serta bahan anti Stripping Wetfix Be.

\section{HASIL dan PEMBAHASAN}

Hasil yang didapatkan dari pengujian sifat fisik agregat yang telah di lakukan di laboratorium dapat dilihat pada Tabel 1 dan Tabel 2.

Dari hasil pengujian sifat fisik agregat, baik untuk agregat halus maupun agregat kasar semuanya memenuhi Spesifikasi Umum Bidang Jalan dan Jembatan Pusat Litbang Pd-T-04-2005-B [5]. Adapun hasil pengujian aspal yang telah dilakukan, untuk titik lembek dengan kadar Wetfix Be $0.4 \%$ serta daktilitas dengan kadar Wetfix Be $0.2 \%$ dan $0.4 \%$ nilainya tidak memenuhi spesifikasi [6].

\section{Hasil Pengujian Marshall Tahap Pertama}

Pengujian Marshall tahap pertama ini bertujuan untuk mendapatkan Kadar Aspal Optimum (KAO), yang akan di gunakan untuk pengujian Marshall tahap kedua.

Setelah seluruh properties aspal diketahui, maka dapat ditentukan kadar aspal optimum dari pengujian Marshall ini. Untuk mendapatkan kadar aspal optimum dibuatlah suatu grafik Marshall pada Gambar 1.

Dari hasil nilai karakteristik campuran yang dihasilkan pada pengujian Marshall pada Tabel 4., berdasarkan spesifikasi serta hasil analisis, diketahui seluruh parameter Marshall yang memenuhi persyaratan terletak pada rentang kadar aspal 5,5\% - 6.5\%. Dari hasil tersebut dapat disimpulkan bahwa:

$$
\begin{gathered}
\text { Kadar Aspal Optimum }=\{(5,0 \%+ \\
6.5 \%): 2\}=6.0 \%
\end{gathered}
$$

\section{Hasil Pengujian Marshall Tahap Kedua}

Setelah di dapat kan KAO 6\%, maka dilakukan pengujian Marshall tahap kedua dengan penambahahan Wetfix Be $0.0 \%, 0.2 \%, 03 \%$, dan $0.4 \%$ dari KAO. Berikut hasil pengujian Marsahall tahap kedua, dapat dilihat paga Tabel 3.

Dari perhitungan stabilitas Marshall sisa dengan membandingkan antara stabilitas perendaman 24 jam dengan stabilitas perendaman 30 menit. Berikut hasil perhitungan stabilitas sisa dengan menggunakan Wetfix $B E$ dengan kadar $0.2 \%, 0.3 \%$, dan $0.4 \%$.

Dari Tabel 4 didapatkan bahwa untuk nilai stabilitas sisa dengan menggunakan Wetfix BE $0.2 \%, 0.3 \%$, dan $0.4 \%$ adalah $91.9 \%, 96.9 \%$, dan $92.6 \%$. Nilai tersebut memenuhi persyaratan SNI 8198-2015 yaitu minimal $90 \%$. Nilai stabilitas sisa yang paling tinggi di dapatkan pada kadar Wetfix BE $0.3 \%$ dengan persentase peningkatan $6.72 \%$ dari kadar Wetfix $B E$ $0.0 \%$ (Gambar 2).

Maka dari itu beton aspal dengan kadar Wetfix BE $0.30 \%$ memiliki ketahanan yang tinggi terhadap kerusakan yang ditimbulkan oleh pengaruh air.

\section{Kadar Wetfix $B e$ yang digunakan adalah $=0,3 \%$}

\section{Hasil Pengujian Marshall Tahap Ketiga}

Padat tahap ini benda uji ditambahkan Wetfix Be dengan kadar 0.3\%, dari kadar aspal optimum yang telah didapat sebesar $6.0 \%$, dengan variasi jumlah 
tumbukan $2 \times 50,2 \times 75,2 \times 100,2 \times 125$, dan $2 \times 150$. Sedangkan analisa pengujian benda uji Marshall tahap ketiga dapat dilihat pada Tabel 5.

Dari Gambar 3. Diperoleh jumlah tumbukan optimum 2x100

Dengan Kadar Aspal 6\% dan Kadar Wetfix Be $0.3 \%$, jumlah tumbukan optimum $2 \times 100$, dari grafik diperoleh sifat-sifat mekanis yang terdapat pada Tabel 6.

\section{KESIMPULAN}

Hasil analisis menunjukkan bahwa:

Hasil pengujian Marshall tahap pertama diperoleh KAO sebesar 6\%, dari pengujian Marshall tahap kedua dengan bahan tambah Wetfix Be, diperoleh kadar Wetfix Be 0,3\%.

Dengan KAO 6\%, kadar Wetfix Be 0,3\%, dan variasi tumbukan $2 \times 50 ; 2 \times 75$; $2 \times 100 ; \quad 2 \times 125 ; \quad 2 \times 150$ pengujian Marshall tahap ketiga diperoleh Jumlah Tumbukan Optimum 2x100; Rongga terhadap Agregat (VMA) 17,50\%; Rongga Terisi Aspal (VFB) 76,50\%; Rongga terhadap Campuran (VIM) 4,00\%; Stabilitas 1800,00 kg; Kelelehan 3,75 mm; dan Marshall Quontient $500,00 \mathrm{~kg} / \mathrm{mm}$

\section{UCAPAN TERIMAKASIH}

Dalam kesempatan ini penulis banyak mengucapkan terimakasih yang sedalam-dalamnya kepada semua pihak yang telah membantu penelitian ini terutama kepada Kepala PPPM Politeknik Negeri Jakarta, yang telah menyalurkan dana dari DIPA Politeknik Negeri Jakarta dan Kusno, alumni Jurusan Teknik Sipil yang sudah membantu pada proses pelaksanaan dan pengambilan data di laboratorium.

\section{DAFTAR PUSTAKA}

[1] Mashuri, 2008, Pengaruh Penggunaan Serbuk Arang Tempurung Kelapa Dan Variasi Jumlah Tumbukan Terhadap Karakteristik Campuran Beton Aspal Jurnal "MEKTEK" TAHUN X NO.1 JANUARI 2008, Fakultas Teknik Universitas Tadulako, Palu)

[2] Sastra, Hadi. 2009. Pengaruh Variasi Jumlah Tumbukan Pada Lapisan Aspal Buton Beragregat (LASBUTAH) dengan Modifikasi Campuran Dingin (COLD MIX) Dengan Modifier Pertamax Terhadap Karakteristik Marshall (Tesis). Universitas Muhammadiyah Malang.

[3] Andi, SA, 2010, Variasi Jumlah Tumbukan pada Campuran Beton Aspal terhadap Nilai Density dan Void in The Mix (VITM), GAMMA, Volume 5, Nomor 2, Maret 2010: 90 $-97$

[4] SNI 8198:2015, Spesifikasi Campuran Beraspal Panas Bergradasi Menerus (Laston), Badan Standarisasi Nasional. 
Tabel 1. Hasil Pengujian Agregat Halus dan Agregat Kasar

\begin{tabular}{|c|c|c|c|c|c|}
\hline \multirow{2}{*}{ Pengujian } & \multirow{2}{*}{ Sat } & \multicolumn{2}{|c|}{ Persyaratan } & \multirow{2}{*}{ Hasil } & \multirow{2}{*}{ Ket. } \\
\hline & & Min & Mak & & \\
\hline \multicolumn{6}{|l|}{ BJ Agregat Halus } \\
\hline - Bulk & & 2.5 & - & 2.53 & Memenuhi syarat \\
\hline$-\mathrm{SSD}$ & & 2.5 & - & 2.59 & Memenuhi syarat \\
\hline - Semu & & 2.5 & - & 2.71 & Memenuhi syarat \\
\hline Penyerapan Air & $\%$ & - & 3 & 2.67 & Memenuhi syarat \\
\hline Kadar Lumpur & $\%$ & - & 8 & 5.50 & Memenuhi syarat \\
\hline \multicolumn{6}{|l|}{ BJ Agregat Kasar } \\
\hline - Bulk & & 2.5 & - & 2.59 & Memenuhi syarat \\
\hline$-\mathrm{SSD}$ & & 2.5 & - & 2.64 & Memenuhi syarat \\
\hline - Semu & & 2.5 & - & 2.74 & Memenuhi syarat \\
\hline Penyerapan Air & $\%$ & - & 3 & 2.15 & Memenuhi syarat \\
\hline Kadar Lumpur (\%) & & - & 1 & 0.84 & Memenuhi syarat \\
\hline
\end{tabular}

Tabel 2. Hasil Pengujian Aspal Keras

\begin{tabular}{lccccccc}
\hline & & \multicolumn{3}{c}{ Kadar Wetfix Be } & & \multicolumn{2}{c}{$\begin{array}{c}\text { Spesifikasi } \\
\text { SNI 8198-2015 }\end{array}$} \\
& Sat. & & & & & & Min \\
\cline { 2 - 7 } & & $\mathbf{0 . 0 0 \%}$ & $\mathbf{0 . 2 0 \%}$ & $\mathbf{0 . 3 0 \%}$ & $\mathbf{0 . 4 0 \%}$ & Mak \\
\hline Berat Jenis & - & 1.02 & 1.02 & 1.02 & 1.03 & 0,92 & 1,06 \\
Penetrasi & $\mathrm{mm}$ & 68 & 64 & 65 & 67 & 60 & 70 \\
Titik Lembek & ${ }^{\circ} \mathrm{C}$ & 48.00 & 48.50 & 48.50 & 46.00 & 48 & - \\
Daktilitas & $\mathrm{cm}$ & 103.50 & 71.00 & 101.00 & 77.00 & 100 & - \\
\hline
\end{tabular}

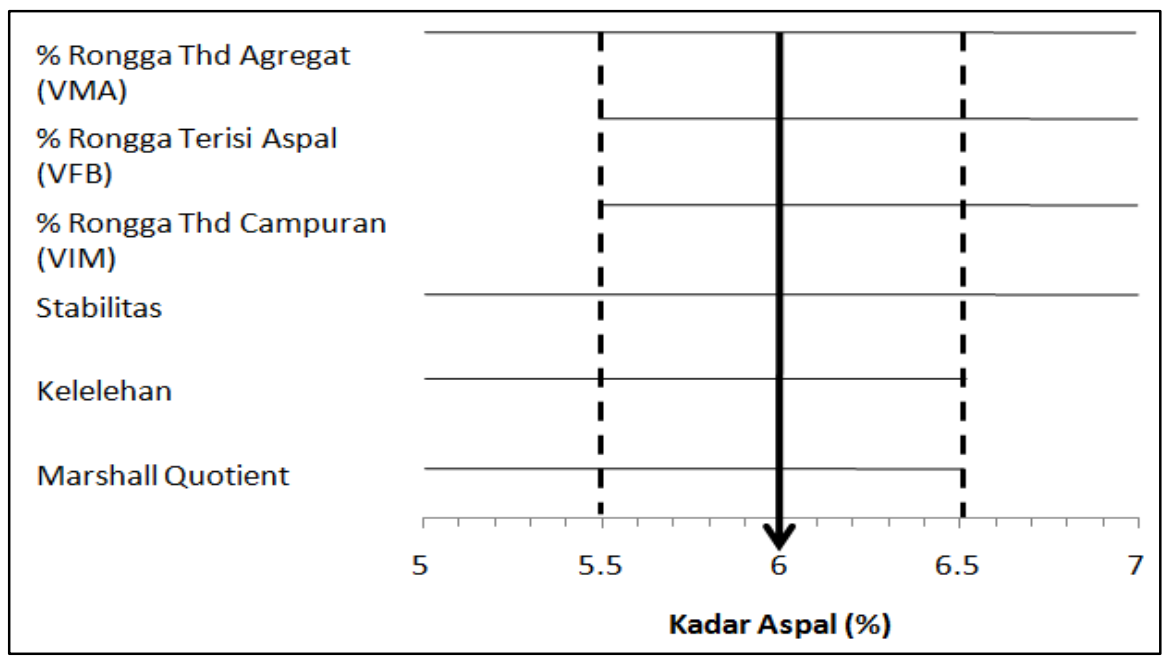

Gambar 1. Penetuan Kadar Aspal Optimum

Tabel 3. Hasil Pengujian Marshall denganWetfix Be 
Eko Wiyono \& Anni Susilowati, Variasi Jumlah Tumbukan...

\begin{tabular}{lccccc}
\hline \multirow{2}{*}{ Sifat Campuran } & \multicolumn{4}{c}{ Persentase Wetfix Be } & \multirow{2}{*}{ Syarat } \\
\cline { 2 - 5 } & $\mathbf{0 . 0 0 \%}$ & $\mathbf{0 . 2 0 \%}$ & $\mathbf{0 . 3 0 \%}$ & $\mathbf{0 . 4 0 \%}$ & \\
\hline \% Rongga Thd Agregat (VMA) & 17.85 & 18.28 & 18.09 & 18.08 & $\min 15$ \\
\% Rongga Terisi Aspal (VFB) & 73.02 & 71.54 & 72.42 & 72.48 & $\min 65$ \\
\% Rongga Thd Camp (VIM) & 4.85 & 5.20 & 4.99 & 4.95 & $3-5$ \\
Stabilitas, (Kg) & 1700.91 & 1186.45 & 1652.49 & 1338.57 & $\min 800$ \\
Kelelehan,(mm) & 3.46 & 4.48 & 3.02 & 3.40 & $3-5$ \\
Marshall Quotient (Kg/mm) & 523.09 & 269.38 & 540.54 & 431.01 & $\min 250$ \\
\hline
\end{tabular}

Tabel 4. Hasil Perhitungan Stabilitas Sisa dengan Menggunakan Wetfix Be

\begin{tabular}{lcccc}
\hline \multicolumn{1}{c}{ Waktu Perendaman } & \multicolumn{4}{c}{ Kadar Wetfix Be } \\
& $\mathbf{0 . 0 0 \%}$ & $\mathbf{0 . 2 0 \%}$ & $\mathbf{0 . 3 0 \%}$ & $\mathbf{0 . 4 0 \%}$ \\
\hline 0.5 Jam (A) & 1700.91 & 1186.45 & 1652.49 & 1338.57 \\
24 Jam (B) & 1544.20 & 1090.60 & 1600.95 & 1239.37 \\
Stabilitas Sisa (B/A) x 100\% & $\mathbf{9 0 . 8 \%}$ & $\mathbf{9 1 . 9 \%}$ & $\mathbf{9 6 . 9 \%}$ & $\mathbf{9 2 . 6 \%}$ \\
\hline
\end{tabular}

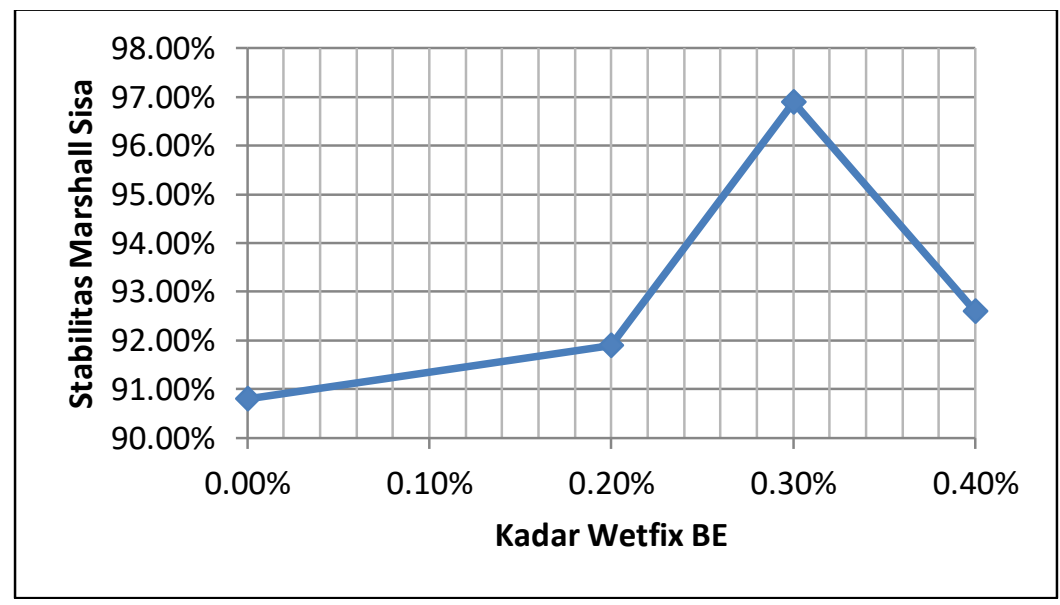

Gambar 2. Grafik Hubungan Kadar Wetfix BE dengan Stabilitas Marshall Sisa

Tabel 5. Hasil Pengujian Marshall dengan Kadar Aspal 6\% dan Kadar Wetfix Be 0.3\% untuk Menentukan Jumlah Tumbukan Optimum.

\begin{tabular}{lcccccc}
\hline \multirow{2}{*}{ Sifat Campuran } & \multicolumn{9}{c}{ Jumlah Tumbukan } & \multirow{2}{*}{ Syarat } \\
\cline { 2 - 6 } & $\mathbf{5 0}$ & $\mathbf{7 5}$ & $\mathbf{1 0 0}$ & $\mathbf{1 2 5}$ & $\mathbf{1 5 0}$ & \\
\hline \% Rongga Thd Agregat (VMA) & 19.30 & 18.08 & 17.55 & 16.53 & 15.59 & $\min 15$ \\
\% Rongga Terisi Aspal (VFB) & 66.88 & 72.50 & 75.71 & 80.68 & 85.37 & $\min 65$ \\
\% Rongga Thd Campuran (VIM) & 6.40 & 4.97 & 4.24 & 3.20 & 2.32 & $3-5$ \\
Stabilitas & 775.26 & 1684.77 & 1727.37 & 1888.43 & 2019.21 & $\min 800$ \\
Kelelehan & 4.33 & 3.80 & 3.75 & 3.43 & 3.43 & $3-5$ \\
Marshall Quotient & 169.65 & 445.02 & 479.35 & 518.40 & 599.91 & $\min 250$ \\
\hline
\end{tabular}


Eko Wiyono \& Anni Susilowati, Variasi Jumlah Tumbukan...

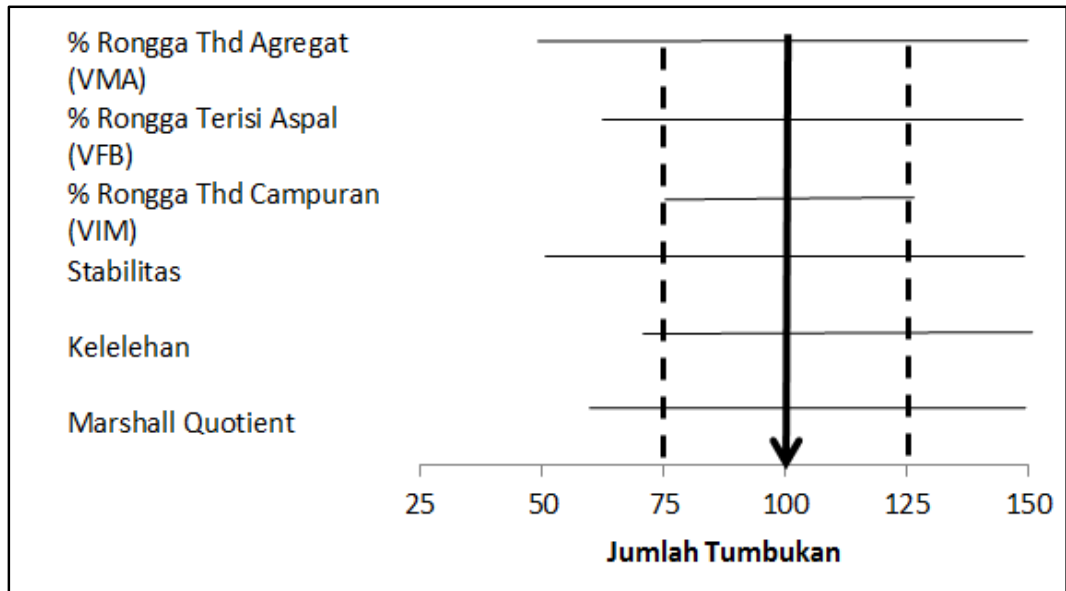

Gambar 3. Penentuan Jumlah Tumbukan Optimum

Tabel 6. Hasil Sifat-sifat Mekanis pada Jumlah Tumbukan Optimum

\begin{tabular}{lccc}
\hline \multicolumn{1}{c}{ Sifat Campuran } & $\begin{array}{c}\text { Kadar Aspal } \\
\mathbf{6 , 0 \%}\end{array}$ & Syarat & Keterangan \\
\hline \% Rongga terhadap agregat (VMA) & 17,50 & $\min 15$ & memenuhi \\
\% Rongga Terisi Aspal (VFB) & 76,50 & $\min 65$ & memenuhi \\
\% Rongga Terhadap Campuran & 4,00 & $3-5$ & memenuhi \\
(VIM) & & & \\
Stabilitas (kg) & 1800 & $\min 800$ & memenuhi \\
Kelelehan (mm) & 3,75 & $2-4$ & memenuhi \\
Marshall Quotient (kg/mm) & 500,00 & $\min 250$ & memenuhi \\
\hline
\end{tabular}

